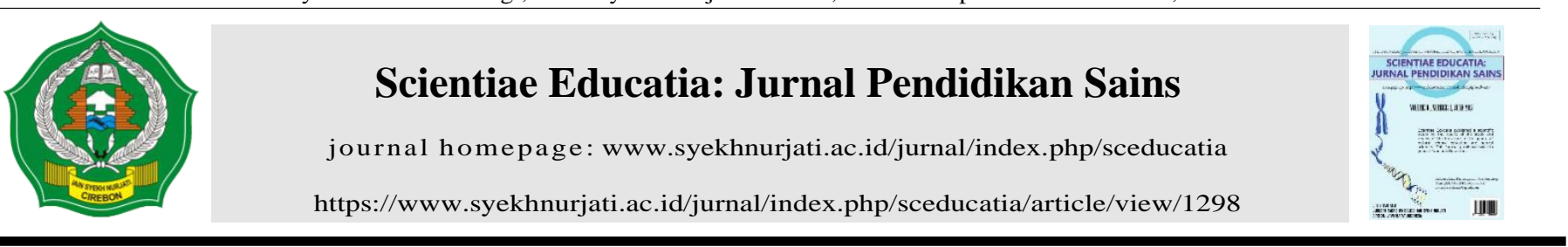

\title{
Kajian Etnobotani Bambu Mayan (Gigantochloa robusta Kurz.) Di Kecamatan Sobang Pandeglang Banten
}

\author{
Riki Rikardo \\ Departemen Biologi, Fakultas Sains dan Farmasi Universitas Mathla'ul Anwar Banten

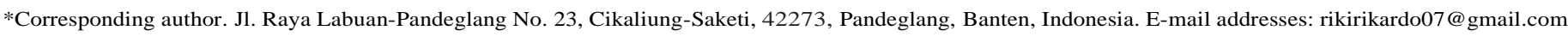

a r t i c 1 e i n f o

Article history:

Received 27 February 2017

Received in revised form 18 June

2017

Accepted 19 June 2017

Available online June 2017

Keywords:

ethnobotany

Gigantochloa robusta Kurz

important value

sobang district

Kata Kunci:

etnobotani

Gigantochloa robusta Kurz

nilai penting

Kecamatan Sobang

\section{a b s t r a c t}

Bamboo is a plant that grows in clump scattering in the tropical, subtropical and temperate region. Bamboo can grow in dry to wet tropical climate, fertile soil conditions or less fertile, and from the $0 \mathrm{~m}$ to $4000 \mathrm{~m}$ above sea level, and from flat to mountain slopes or cliffs of the river. Bamboo is widely available around Pandeglang regency, Banten. The aims of this study to understand the interaction and utilization of bamboo by communities around the District Sobang with the ethnobotanical approach. Ethnobotany deepens the relationship between human culture and nature around it. This research focuses on the perceptions and concepts of cultural groups in society, including the knowledge system of its members to face their life scope. This study used a survey method, direct exploration and interviews on community Sobang District of Pandeglang Banten by age group using a questionnaire to determine the level of public knowledge about the utilization of Gigantochloa robusta Kurz.Based on this research that has been done that the District Public Sobang have relationships and interactions of the Gigantochloa robusta Kurz. The Community uses it as material traditional technology, craft/commercial, heavy construction, foods, customs, light construction, traditional medicine and other benefits. Utilization of traditional technology is the most widely utilized.

Bambu merupakan tanaman berumpun. Tanaman ini tumbuh tersebar di daerah tropis, sub tropis dan daerah beriklim sedang. Bambu dapat tumbuh pada iklim kering sampai tropika basah, pada kondisi tanah subur atau kurang subur dari dataran 0m sampai $4000 \mathrm{~m}$ diatas permukaan laut. Mulai dari tempat datar sampai lereng-lereng gunung atau tebing-tebing sungai. Bambu banyak terdapat di sekitar Kecamatan Sobang. Tujuan penelitian ini untuk mengetahui pemanfaatan bambu oleh masyarakat di sekitar Kecamatan Sobang yang dikaji secara etnobotani. Penelitian ini lebih mengutamakan pada persepsi dan konsepsi budaya kelompok masyarakat, yang dipelajari adalah sistem pengetahuan anggotanya dalam menghadapi lingkup hidupnya. Penelitian ini menggunakan metode survei, eksplorasi langsung dan wawancara pada masyarakat Kecamatan Sobang Kabupaten Pandeglang Banten. Berdasarkan kelompok umur menggunakan kuesioner untuk mengetahui tingkat pengetahuan masyarakat tentang pemanfaatan Gigantochloa robusta Kurz. Hasil penelitian yang telah dilakukan bahwa Masyarakat Kecamatan Sobang memiliki hubungan dan interaksi terhadap Bambu Mayan. Masyarakat memanfaatkannya sebagai bahan teknologi tradisional, kerajinan/komersil, konstruksi berat, makanan, adat-istiadat, konstruksi ringan, obat tradisional dan manfaat lainnya. Pemanfaatan sebagai teknologi tradisional paling banyak di manfaatkan.

2017 Scientiae Educatia: Jurnal Pendidikan Sains

\section{Pendahuluan}

Tumbuhan di Indonesia dimanfaatkan untuk memenuhi kebutuhan hidup, misalnya untuk kebutuhan pangan, obatobatan, kosmetik dan bahan pestisida. Pengetahuan itu diperoleh berdasarkan pengalaman praktis dan pengetahuan tidak tertulis, yang diwariskan dari generasi ke generasi berikutnya (Supriati, dkk. 2013). Bambu memegang peranan sangat penting dalam kehidupan masyarakat di Indonesia. Bambu dikenal memiliki sifat-sifat yang baik untuk dimanfaatkan berupa batang yang kuat, serta kulit batang yang mudah dibentuk. Bambu banyak ditemukan di sekitar pemukiman daerah pedesaan, sehingga bambu menjadi tanaman serbaguna bagi masyarakat pedesaan (Munziri dan Mukarlina, 2013). Bambu adalah tumbuhan serbaguna, cepat tumbuh serta memiliki peranan yang penting dalam kehidupan dan budaya masyarakat (Razvi, $d k k$. 2011). Bambu telah digunakan secara luas sebagai bahan bangunan di seluruh dunia. Dari bangunan tradisional untuk proyek arsitektur yang inovatif, bambu telah menunjukkan kesesuaian berdasarkan pada berat badan gabungan rendah, kekuatan tinggi, keindahan dan daya tahan (Singh,dkk. 2013). Bambu digunakan dalam hal teknis maupun non teknis (Sevalia, $d k k$. 2013).

Banyaknya manfaat bambu mayan perlu dikaji dalam etnobotani. John William Harshberger (1895) seorang ahli botani dari Amerika adalah pencetus ide dan gagasan tentang pandangan etnobotani yang kemudian berkembang sejalan dengan 
berbagai bentuk pendekatan formal dalam menganalisis materi etnografi dan botani. Etnobotani merupakan cabang ilmu yang mendalami hubungan budaya manusia dan alam nabati di sekitarnya (Meita, 2013). Kajian etnobotani dapat melakukan evaluasi terhadap tingkat pengetahuan dan fase-fase kehidupan masyarakat dalam kaitan dengan pemaknaan dan penggunaan tumbuhan di dalam lingkup kehidupan sehari-hari (Walujo, 2009). Etnobotani melingkupi tiga hal yaitu jenis tumbuhan yang bermanfaat tidak hanya dalam budaya barat tetapi juga non-barat; kognisi terkait tumbuhan termasuk bagaimana manusia membangun persepsi tentang tumbuhan, soal ethno sains dan linguistik; dan ekologi terkait upaya konservasi dan perilaku masyarakat berinteraksi dengan tumbuhan (Sudana, $d k k .2012$ ).

Pokok-pokok perhatian etnobotani meliputi; jenis-jenis tumbuhan yang dimanfaatkan serta cara penggunaannya, persepsi, sikap dan perilaku masyarakat, serta penggolongan-penggolongan sistem penamaan yang diberikan terhadap tumbuhan, vegetasi dan kelimpahan jenis, potensi ekonomi tumbuhan dan lingkungan, koleksi spesimen, dan koleksi jenis (Harsono dan Martina, 1998). Menurut Purwanto dan Walujo (1992), tumbuhan berguna dikelompokkan berdasarkan pemanfaatannya antara lain tumbuhan sebagai bahan pangan, sandang, bangunan, obat-obatan, kosmetik, alat rumah tangga dan pertanian, talitemali, anyaman, pelengkap upacara adat, kegiatan sosial, minuman dan kesenian (Febry, 2011).

Banyaknya potensi dan persebaran bambu mayan serta pentingnya pengetahuan maka perlu dilakuan penelitian. Penelitian bertujuan untuk mengetahui interaksi masyarakat sekitar terhadap bambu mayan dan kajian etnobotani bambu mayan di Kecamatan Sobang Pandeglang Banten.

\section{Metode Penelitian}

Penelitian ini menggunakan metode survei, eksplorasi langsung dan wawancara pada masyarakat Kecamatan Sobang Pandeglang Banten berdasarkan kelompok umur menggunakan kuisioner untuk mengetahui tingkat pengetahuan masyarakat tentang pemanfaatan Bambu Mayan dalam kajian etnobotani.

Alat dan bahan; 1) kamera digital, pensil, pulpen, buku tulis, gunting, sarung tangan, tali, pedoman wawancara terstruktur, 2) bahan yang digunakan yaitu Spesimen Bambu Mayan yang berada di lokasi penelitian, Kecamatan Sobang Kabupaten Pandeglang Banten.

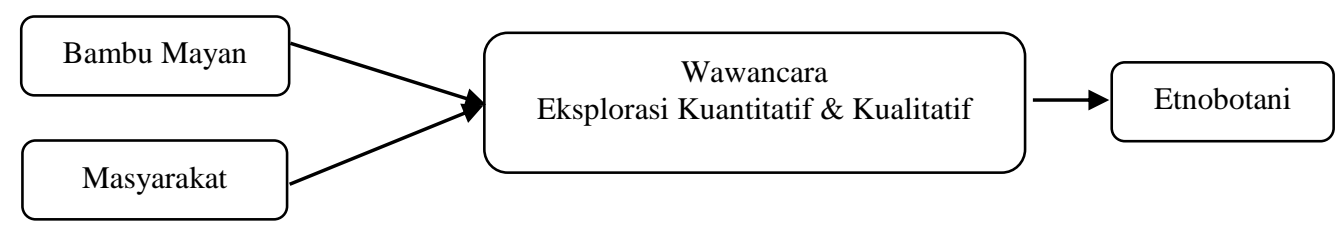

Gambar 1. Bagan Proses Penelitian

Analisis data pendugaan nilai manfaat dari setiap jenis $\boldsymbol{s}$ untuk setiap informan $\boldsymbol{I}$, UVis didefinisikan sebagai:

$$
\begin{aligned}
& \mathrm{t}=1 \\
& \text { UVis }
\end{aligned}=\frac{\begin{array}{c}
\text { nis } \\
\text { (Uist }
\end{array}}{\text { nis }}
$$

dimana (Uist $=$ jumlah manfaat yang disebutkan pada kejadian $\boldsymbol{t}$ untuk jenis $\boldsymbol{s}$ oleh narasumber $\boldsymbol{I}$ dan $\boldsymbol{n i s}=$ jumlah kejadian $\boldsymbol{I}-\boldsymbol{t}$ untuk $\boldsymbol{s}$ dengan narasumber $\boldsymbol{I}$, kemudian pendugaan total nilai manfaat untuk setiap jenis $\boldsymbol{s}, \boldsymbol{U} \boldsymbol{v}$ adalah :

$$
\begin{gathered}
\mathrm{i}=1 \\
\text { UVs }
\end{gathered}=\frac{\substack{\mathrm{n} \\
\mathrm{nist}}}{\mathrm{ns}}
$$

di mana $\boldsymbol{n} \boldsymbol{s}=$ jumlah narasumber yang diwawancarai untuk jenis $\boldsymbol{s}$ (Walujo,1998).

\section{Hasil dan Pembahasan}

\section{Nilai Kegunaan Bambu Mayan}

Terintegrasinya bambu dengan hampir semua kebutuhan dan kegiatan masyarakat menjadikan bambu sebagai tanaman serba guna atau multifungsi. Diperoleh data awal dari 120 informan, 24 informan tidak mengetahui tentang Bambu Mayan dengan perbandingan $80 \%: 20 \%$. Berdasarkan hasil survei mayoritas dari informan yang tidak mengetahui bambu mayan berusia antara 12 - 25 tahun atau dalam kategori remaja hal ini dikarenakan belum adanya pemahaman dan pengalaman informan.

Nilai emik Bambu Mayan (Gigantochloa Robusta Kurz.) dibagi kedalam 8 kategori ,yaitu teknologi tradisional, kerajinan/komersil, konstruksi berat, makanan, adat-istiadat, konstruksi ringan, obat tradisional, dan manfaat lainnya (Gambar 2). 


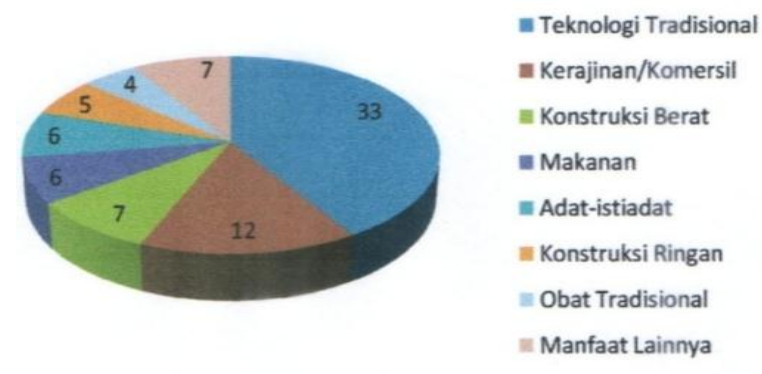

Gambar 2. Kategori pemanfaatan bambu mayan

\section{Teknologi Tradisional}

Bambu Mayan (Gigantochloa robusta Kurz.) dimanfaatkan sebagai teknologi tradisional, yaitu kayu bakar, arang, getek(rakit), tangga, rak piring, rajeg(pagar), sasak, cukang (jembatan), kompos, amben, plupuh, kursi, meja, pananggung (pikulan), gribig (bilik), kentongan/ tongtrong, caping (cotom), loloco, lodong, gantar (galah), sampayan, talang air, pancuran air, taplakan, penggaruk, ancak (tirai), para, pot bunga, gapura, tusuk sate, sumpit, lalangitan, cetakan gula (Tabel 1).

Mayoritas masyakat Kecamatan Sobang masih menggunakan teknologi tradisional dalam kehidupannya. Ini terlihat dari banyaknya jenis pemanfaatan bambu mayan sebagai teknologi tradisional. Pada umumnya peralatan teknologi tradisional cenderung untuk memanfaatkan bahan yang tersedia di lingkungan alam sekitar.

Tabel 1. Nilai UVIs Kategori Teknologi Tradisional

\begin{tabular}{|c|c|c|c|c|c|c|c|}
\hline Pemanfaatan & Nilai UVIs & Pemanfaatan & Nilai UVIs & Pemanfaatan & $\begin{array}{l}\text { Nilai } \\
\text { UVIs }\end{array}$ & Pemanfaatan & Nilai UVIs \\
\hline Pagar & 2,667 & Penggaruk/ Kokoreh & 0,600 & Meja & 0,267 & Sumpit & 0,200 \\
\hline Ancak/ Tirai & 1,400 & Lodong & 0,400 & Tusuk Sate & 0,267 & Para & 0,133 \\
\hline Tongtrong/Kentongan & 1,200 & Lalangitan & 0,400 & Rak Piring & 0,200 & Pot Bunga & 0,133 \\
\hline Amben & 1,200 & Pancuran air & 0,333 & Loloco & 0,200 & Arang & 0,133 \\
\hline Tangga & 0,933 & Caping/Cotom & 0,267 & Sampayan & 0,200 & $\begin{array}{l}\text { Cetakan } \\
\text { Gula }\end{array}$ & 0,133 \\
\hline
\end{tabular}

Kayu bakar masih banyak dimanfaatkan oleh masyarakat karena mayoritas masyarakat sebagai petani. gas LPG belum banyak digunakan masyarakat seperti di kota besar. Arang bambu mempunyai fungsi yang sama dengan arang kayu. Nilai kalor arang bambu rata-rata $6602 \mathrm{kal} / \mathrm{gr}$ dan yang paling baik dijadikan arang adalah bambu ater karena sifat arang yang dihasilkan relatif sama dengan sifat arang kayu bakau (Batubara, 2002).

Taraje (Tangga) dibuat dengan struktur rakit. Bambu disusun atau diikat dengan pasak dengan cara memberi lubang pada masing-masing ujung (El-Kabumaini dan Tjetjep, 2008). Tangga yang dalam bahasa jawa dikenal sebagai anda atau taraje dalam bahasa sunda memiliki dua jenis yaitu tangga laki-laki dan tangga perempuan. Antara tangga laki-laki dan tangga perempuan memiliki perbedaan pada induk tangganya, dimana tangga perempuan memiliki dua induk tangga pada sisi kiri dan sisi kanan sedangkan tangga laki-laki hanya memiliki satu induk tangga. Tangga laki-laki digunakan untuk memanjat pohon yang tinggi seperti mengambil nira aren dan pepohonan dengan ketinggian lebih dari 5 meter sedangkan tangga perempuan digunakan dengan ketinggian kurang dari 5 meter. Bilik atau gribigdibuat dari anyaman bambu yang dipakukan pada kayu. Bilik atau gribig digunakan sebagai pengganti papan dinding yang biasanya terbuat dari papan kayu. Bilik memiliki beberapa variasi, bilik biasa, bilik motif dan bilik hinis. Cukang atau jembatan dipergunakan sebagai sarana menyebrangi sungai. Biasanya disusun dari beberapa gelondongan bambu yang diikat menjadi satu. Cukang masih menjadi sarana penyebrangan yang banyak digunakan sebagai penyebrangan. Caping atau cotom ditinjau dari segi kegunaannya, sebenarnya tidak semata-mata dipergunakan pada saat seorang petani melakukan pekerjaan menggaru saja. Tetapi juga dipergunakan pula pada saat melakukan pekerjaan, menyabit rumput, menyangkul, mengetam padi dan lain sebagainya (Soetjipto dan Soenarto, 1990).

Sumpit adalah alat makan berbentuk dua batang bambu yang panjang dan dipegang diantara jari-jari salah satu tangan. Sumpit digunakan untuk menjepit, memindahkan makanan dari satu wadah dan memasukkan makanan ke dalam mulut. Sumpit banyak digunakan di tempat penjual mie ayam, mie bakso atau hanya tempat memesan Mie Instant rebus selalu 
ditemukan sumpit. Kentongan atau tongtrong digunakan sebagai alat komunikasi, yaitu untuk mengumpulkan warga sekitar ketika terjadi suatu peristiwa tertentu. Anak-anak atau remaja pada bulan puasa menggunakan kentongan untuk membangunkan warga saat melaksanakan saur.

Pengertian sistem teknologi tradisional masih bergerak dalam bidang pemenuhan kebutuhan hidup baik yang material maupun yang spiritual dengan meletakkan titik berat perhatian pada alat-alat yang dipergunakan. Alat yang dipergunakan untuk memenuhi kebutuhan dari masa ke masa berkembang sesuai dengan perkembangan kebudayaan masyarakat pendukungnya. Alat-alat ini dari generasi ke generasi sudah ada sejak turun temurun yang diwariskan dari generasi ke generasi (Soetjipto dan Soenarto, 1990).

Bambu sebagai furniture harus memenuhi beberapa syarat. Selain warna yang menarik juga dapat dibentuk secara istimewa dengan nilai seni yang tinggi tetap memenuhi kekokohannya. Olesan pengawet dan penghias, seperti pernis meningkatkan keawetan dan penampilan dengan tetap berkesan alami. Perkakas rumah tangga dan hiasan dari bambu digemari karena disamping tidak berkarat juga mencerminkan kesederhanaan tapi tetap anggun (Batubara, 2002). Bambu yang digunakan sebagai furniture harus memiliki sifat buluh berdiameter $15-20 \mathrm{~cm}$, dinding tebal, buku-buku tidak kasar, bekas mata tunas tidak menonjol (Sutarno, $d k k .1996)$.
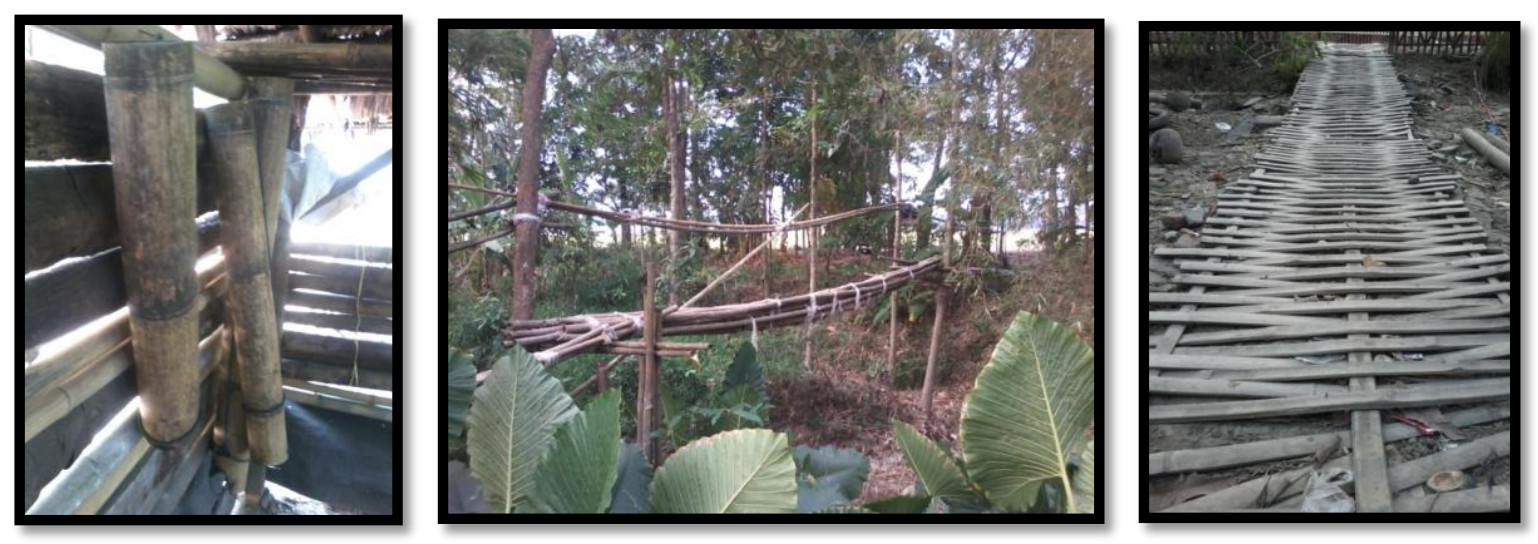

Gambar 3. a. lodong b. Jembatan (cukang) c. Sasak

Masyarakat sobang memanfaatkan bambu sebagai furniture seperti meja, rak piring, gapura dan pot bunga

\section{Kerajinan/Komersil}

Kerajinan sangat erat dengan kreativitas masyarakat. Kerajinan dengan nilai seni tinggi menandakan tingginya daya kreativitas masyarakat tersebut. Penerapannya masyarakat memanfaatkannya sebagai angklung, tusuk gigi, layangan, ceting/bakul, cepon/boboko, kalo, tolok, pengangen, tampah, kipas, haseupan, sair/irig/ayakan.

Ada beberapa produk dari bambu seperti: kipas, ayakan, tampah, kukusan diproduksi secara komersial oleh masyarakat di sobang. Perajin yang akan memproduksi kerajinannya akan memilih jenis bambu yang sesuai dengan keinginan dan tujuan. Teknik pembakaran dilakukan dengan memanaskan besi atau alat yang sudah dipersiapkan ke dalam tungku pemanas lalu dibuat motif atau gambar sesuai selera pembuat. Teknik pengecatan dengan menggunakan jenis-jenis cat yang biasa dijual di toko untuk memperoleh warna tertentu biasanya kurang disukai konsumen (Tabel 2).

Tabel 2. Nilai User Value Indeks kategori kerajinan/komersil

\begin{tabular}{lclclc}
\hline \multicolumn{1}{c}{ Pemanfaatan } & Nilai UVIs & \multicolumn{1}{c}{ Pemanfaatan } & Nilai UVIs & \multicolumn{1}{c}{ Pemanfaatan } \\
\hline Hihid/Ilir/ Kipas & 2,042 & Cepon/ Boboko & 1,225 & Pengangen & 0,233 \\
\hline Sair/ Irig/ Ayakan & 2,042 & Bakul/Ceting & 0,700 & Layangan & 0,175 \\
\hline Nyiru/ Namper/ Tampah & 1,750 & Tusuk Gigi & 0,233 & Kalo & 0,117 \\
\hline Haseupan/ Kukusan & 1,692 & Tolok & 0,233 & Angklung & 0,117 \\
\hline
\end{tabular}

Alat musik angklung merupakan alat musik bernada ganda yang secara tradisional berkembang dalam masyarakat Sunda di pulau jawa bagian barat. Pembuatan angklung bambu harus memiliki sifat buluh panjang dan diameter ruas bervariasi, ketebalan buluh bervariasi, mampu menghasilkan nada yang dikehendaki, kadar air buluh rendah, dan mudah dikeringkan (Sutarno, dkk. 1996). Cepon atau boboko dibuat dari bambu yang dianyam. Bentuknya menyerupai tempat nasi atau wakil/ceting/bakul, tetapi tidak ada tempat duduknya di bagian bawah. Bentuknya yang bulat dapat dikatakan mirip mangkuk yang besar. Cepon digunakan sebagai tempat bibit, baik bibit padi, jagung, kacang panjang dan sebagainya. Selain sebagai tempat menyimpan bibit, cepondigunakan dalam kegiatan penanaman di tanah darat atau tegalan, agar mudah mengambilnya sehingga penanaman dapat dilakukan dengan mudah (Dakung, dkk. 1989). Bakul dan nyiru juga dimnafaatkan oleh masyarakat Dayak Kanayatn, dibuat dengan cara dianyam (Munziri dan Mukarlina, 2013). Pembuatan kerajinan buluh bersifat mudah dibelah dan dibentuk dengan alat yang sederhana. Rimpang dan daun mempunyai bentuk yang khas, artistik, serat buluh lemas (Soetarno, $d k k$. 1996). 


\section{Konstruksi Berat}

Bambu mayan digunakan masyarakat Kecamatan Sobang sebagai: kerangka bangunan, saung, rumah, usuk, reng, bagang (keramba), panggung. Bambu masih banyak digunakan sebagai konstruksi dikarenakan masih banyaknya tegakkan bambu dan tahan terhadap gempa (Tabel 3).

Tabel 3. Nilai User Value Indeks Kategori Konstruksi Berat

\begin{tabular}{lclc}
\hline Pemanfaatan & Nilai UVIs & Pemanfaatan & Nilai UVIs \\
\hline Kerangka Bangunan & 0,450 & Rumah & 0,250 \\
\hline Reng & 0,400 & Saung & 0,200 \\
\hline Usuk/layes(kaso) & 0,350 & Panggung & 0,200 \\
\hline Bagang/ Keramba & 0,250 & & \\
\hline
\end{tabular}

Sebagai bahan bangunan alternatif pengganti kayu, para pengguna pada dasarnya tentu akan mempertimbangkan beberapa aspek penting, seperti kualitas yang meliputi kekuatan dan ketahanan bambu sebagai bahan alternatif pengganti kayu tentunya dipilih bambu yang batangnya lurus, berdiameter batang sedang hingga besar bulat akan digunakan sebagai pilar atau tiang rumah, berdinding buluh tebal, dan tahan terhadap serangan hama terutama bubuk batang. Secara umum kekuatan bambu setara baja ringan dan padat seperti serat karbon (Sakaray, $d k k$. 2012).

Rumah-rumah sederhana tempo dulu pada dasarnya menggunakan bahan-bahan alami yang mudah diperoleh di lingkungan sekitarnya seperti bambu, kayu, alang-alang, dan rumbia. Seiring perkembangan teknologi, bahan-bahan alami tersebut kadang banyak ditinggalkan. Baik untuk bangunan volume yang besar maupun kecil. Namun kemudian manusia kini seperti menyadari kembali akan kerinduannya menghadirkan bahan alami bagi tempat tinggalnya, temapt usaha maupun satu tempat lain di dalam mewadahi aktivitasnya sehari-hari (El-Kabumaini dan Tjetjep, 2013). Bambu bersama bahan organik lainnya banyak digunakan pada pembangunan rumah rakyat pedesaan. Perkembangan bahan dasar dan kebutuhan perumahan rakyat yang sederhana, maka pembangunan rumah bambu sesuai untuk membantu rakyat yang berpenghasilan rendah, terutama di daerah yang mempunyai ketersediaan bambu (Batubara, 2002). Material terbarukan seperti halnya kayu, bambu sesungguhnya merupakan pilihan yang baik ditinjau dari sisi keberlanjutan karena dapat ditanam kembali, namun maraknya kasus penebangan liar dan pengrusakan hutan, penggunaan kayu, terutama kayu jenis keras, seperti jati, ulin dan lainnya, untuk bahan bangunan menjadi hal yang sensitive di Indonesia. Material yang bersifat dapat digunakan atau dipasang kembali jika bangunan diruntuhkan lebih disarankan untuk digunakan (Harso, 2010).

Bambu yang dipergunakan sebagai konstruksi atau bahan bangunan sebaiknya diawetkan terlebih dahulu. Pengawetan dilakukan dengan merendam dalam air selama beberapa minggu kemudian dikeringkan atau dilakukan pengasapan belerang agar hama yang ada mati dan tidak dikunjungi oleh hama perusak. (Batubara, 2002). Di India bambu digunakan sebagai perancah. Perancah bambu dianggap sebagai jenis yang dominan di industri konstruksi lokal selama bertahun-tahun terutama karena biaya yang rendah (Bambhava, dkk. 2013). Bambu dapat menggantikan 70\% dari baja dan kayu yang digunakan dalam konstruksi dan mengurangi biaya sebesar 40\% (Syeda dan Shrujal, 2014).

\section{Makanan}

Masyarakat mengolah rebung menjadi gado-gado, sayur santan, urab, risol, lotek, tumis. Rebung bambu biasanya banyak ditemukan pada musim penghujan. Tumbuh dengan cepat dan berusia kurang dari 30 hari. Karena setelah berumur lebih dari 30 hari bambu akan mengeras dan beralih manfaat (Tabel 4).

Tabel 4. Nilai User Value Indeks Kategori Makanan

\begin{tabular}{lclc}
\hline Pemanfaatan & Nilai UVIs & Pemanfaatan & Nilai UVIs \\
\hline Sayur santan & 0,292 & Tumis & 0,167 \\
\hline Urab & 0,208 & Gado-gado & 0,125 \\
\hline Lotek & 0,167 & Risol & 0,083 \\
\hline
\end{tabular}

Di bidang makanan dan sayuran, kelezatan rebung bambu sudah diketahui oleh masyarakat sejak lama. Masyarakat Sobang menyenangi rebung bambu karena rasanya enak, tidak terlalu pahit ataupun tidak terlalu keras dan juga rebungnya besar. Melalui teknik sederhana yaitu dengan mengupas, mengiris, merebus dan kemudian mencucinya rebung sudah siap dipasarkan atau dikonsumsi. Bambu dapat dimanfaatkan sebagai sayuran dalam bentuk rebung. Jenis-jenis tertentu rebungnya dapat dimakan karena kadar HCN kecil atau sama sekali tidak ada, rasanya memenuhi selera, lunak dan warnanya menarik. Kandungan gizinya cukup memadai sebagai sumber mineral dan vitamin (Batubara, 2002). Dayak Kanayatn memanfaatkan rebung untuk makanan yaitu dengan cara ditumis (Munziri dan Mukarlina, 2013).

\section{Adat-istiadat (Ritual)}

Masyarakat di daerah penelitian yang sebagian besar bermata pencaharian sebagai petani juga mengenal berbagai upacara dalam pertanian salah satunya sedekah bumi. Upacara ini ditujukan kepada makhluk-makhluk halus dengan maksud agar mereka tidak marah sehingga hal-hal yang tidak diinginkan tidak terjadi. Selain itu juga merupakan rasa syukur kepada 
Tuhan Yang Maha Esa. Upacara seperti itu dapat terjadi di berbagai jenis lapangan pekerjaan termasuk pertanian. Selain sedekah bumi acara adat yang menggunakan bambu seperti tiang janur, kurung dedes (keranda), tangtang angin, dan palang kuburan (Tabel 5).

Tabel 5. Nilai Pemanfaatan dan User Value Indeks Sebagai Adat-istiadat /Ritual

\begin{tabular}{llll}
\hline \multicolumn{1}{c}{ Pemanfaatan } & Nilai UVIs & Pemanfaatan & Nilai UVIs \\
\hline Taru & 0,633 & Palang Kuburan & 0,133 \\
\hline Tiang Janur & 0,267 & Sedekah Bumi & 0,100 \\
\hline Kurung Dedes (Keranda) & 0,267 & Tang-tang Angin & 0,067 \\
\hline
\end{tabular}

Tiang janur biasanya digunakan sebagai pertanda pada acara pernikahan. Setiap tempat orang melakukan pernikahan dipasang janur yang tiangnya terbuat dari bambu. Hal ini sebenarnya tidak hanya terjadi atau dilakukan oleh masyarakat pedesaan saja tapi juga dilakukan oleh masyarakat diperkotaan. Kurung dedes atau keranda merupakan tempat mengusung jenazah ke kuburan. Masyarakat pedesaan masih banyak menggunakan ini. Hal ini dilakukan dilakukan selain masih banyaknya bambu juga ada adanya rasa takut jika menggunakan keranda yang terbuat dari besi karena ketika ada yang meninggal dunia keranda tersebut akan menimbulkan suara, bergerak-gerak di tempat atau yang lainnya. Selain digunakan sebagai kurung dedes atau keranda juga digunakan untuk palang kuburan atau pertanda kuburan sebagai pengganti kayu. Masyarakat Dayak Kanayatn menggunakannya sebagai tolak bala agar terhindar dari segala bahaya (Munziri dan Mukarlina, 2013).

\section{Konstruksi Ringan}

Konstruksi ringan dimanfaatkan masyarakat sebagai atap, kandang, serekep(kurungan ayam),sangkar ayam, sangkar burung. Pemanfaatan konstruksi ringan masih dilakukan secara tradisional dan memanfaatkan bahan yang ada di lingkungan sekitar (Tabel 6).

Tabel 6. Nilai Pemanfaatan dan User Value Indeks Sebagai Konstruksi Ringan

\begin{tabular}{lclc}
\hline Pemanfaatan & Nilai UVIs & Pemanfaatan & Nilai UVIs \\
\hline Kandang & 0,175 & Sangkar ayam & 0,075 \\
\hline Serekep & 0,125 & Atap & 0,075 \\
\hline Sangkar burung & 0,100 & & \\
\hline
\end{tabular}

Pembuatan kandang ayam atau kambing menggunakan bambu dalam bentuk utuh dan ada pula yang dibelah. Bambu yang digunakan dalam bentuk utuh biasanya dibuat untuk dinding kandang (Munziri dan Mukarlina, 2013).

\section{Obat Tradisional}

Masyarakat di daerah penelitian masih banyak menggunakan bahan alami sebagai obat alternatif salah satunya bambu. Bambu digunakan sebagai obat batuk, turun panas, sesak napas dan penetral racun. Caranya ujung batang bambu dipotong, tetesan air yang keluar dari bekas potongan itu ditampung pada ruas bambu semalaman. Cairan hasil penampungan tersebut (tuak) diminumkan pada penderita sakit (Tabel 7).

Tabel 7. Nilai User Value Indeks Kategori Obat Tradisional

\begin{tabular}{cclc}
\hline Pemanfaatan & Nilai UVIs & Pemanfaatan & Nilai UVIs \\
\hline Obat Batuk & 0,233 & Sesak Napas & 0,050 \\
\hline Turun Panas & 0,117 & Penetral Racun & 0,050 \\
\hline
\end{tabular}

Daun bambu digunakan sebagai anthhelmintic. Tabashir (mama bambu) merupakan stimulant penurun panas, antispasmodic, dan afrodisiak (Kumar, $d k k$. 2010). Penggunaan obat tradisional ini juga banyak digunakan masyarakat Baduy sebagai obat batuk (Iskandar dan Budiawati, 2005). Di Bengkulu Selatan bambu mayan (Gigantochloa robusta Kurz) digunakan sebagai obat diare (Supriati, 2013). Bambu digunakan sebagai obat karena mengandung asetilkolin dan flavonoid yang digunakan sebagai antioksidan (Dharmananda, 2004).

\section{Manfaat Lainnya}

Berbagai keperluan lain yang membutuhkan bambu sebagai bahan baku adalah golodog, lanjaran atau ajir, peletokan, enggrang, ayunan, koci, dan alas pindang (Tabel 8).

Tabel 8. Nilai User Value Indeks Manfaat Lainnya

\begin{tabular}{lrlc}
\hline Pemanfaatan & Nilai UVIs & Pemanfaatan & Nilai UVIs \\
\hline Golodog & 0,067 & Ayunan & 0,017 \\
\hline Ajir/ Lanjaran & 0,092 & Koci & 0,017 \\
\hline Peletokan & 0,033 & Alas Pindang & 0,092 \\
\hline Enggrang & 0,025 & Tiang Antena & 0,033 \\
\hline
\end{tabular}


Golodog merupakan alas tempat menyimpan ember, bak dan lain sebagainya didapur. Golodog banyak ditemukan pada rumah panggung. Lanjaran atau ajir digunakan sebagai penyangga tanaman seperti kacang panjang, timun, dan melon.Enggrang, peletokan dan ayunan merupakan permainan tradisional yang masih banyak ditemukan di daerah penelitian. Sedangkan koci dan alas mindang merupakan pangganti daun pisang.

\section{Simpulan}

Dari hasil penelitian yang dilakukan di Kecamatan Sobang Pandeglang Banten dapat disimpulkan bambu mayan (Gigantochloa robusta Kurz.) masih banyak dimanfaatkan oleh Masyarakat di Kecamatan Sobang Pandeglang Banten. Pemanfaatan bambu mayan (Gigantochloa robusta Kurz.) di Kecamatan Sobang Pandeglang Banten dimasukkan dalam 8 kategori pemanfaatan, yaitu teknologi tradisional, kerajinan/komersil, konstruksi berat, makanan, adat-istiadat, konstruksi ringan, obat tradisional dan manfaat lainnya serta mayoritas masyarakat Kecamatan Sobang memiliki hubungan dan interaksi yang sangat erat dengan alam lingkungannya dalam hal ini bambu mayan (Gigantochloa robusta Kurz.) tercermin dari pengetahuan dan pemanfaatan sehari-hari.

\section{Daftar Pustaka}

Bambhava, H.D., Jayeshkumar P., \& Jaydev J. B. (2013). A Comparative Study on Bamboo Scaffolding and Metal Scaffolding in Construction Industry Using Statistical Methods. Int. JETT. 4(6) : 2330-2337

Basri, E., \&Saefudin. (2012). Sifat Fisik dan Bagan Pengeringan Bambu Mayan (Gigantochloa robusta Kurz). Prosiding Seminar Nasional Masyarakat Peneliti Kayu Indonesia XV.Universitas Hasanudin Makasar.

Batubara, R. (2002). Pemanfaatan Bambu di Indonesia. Program Ilmu Kehutanan Fakultas Pertanian Universitas Sumatera Utara.

Dakung, S., Sindu G., Srie S.S.U., Fadjria N.M., Wahyuningsih, \& Raf D. (1989). Teknologi PertanianTradisional Sebagai Tanggapan Aktif Masyarakat Terhaap Lingkungan di Daerah Pekalongan. Departemen Pendidikan dan Kebudayaan : Jakarta.

Dharmananda, S. (2004). Bamboo as Medicine. Institute of Traditional Medicine Portland. Oregon. P.1-7.

El-Kabumaini, N., \& Tjetejep S.R. (2013). Pemanfaatan Bambu Sebagai Bahan Konstruksi. PT. Pri Delco : Bandung.

Febry, A.A. (2011). Kajian Etnobotani Masyarakat di Sekitar Taman Nasional Gunung Merapi. [Skripsi] Departemen Konservasi Sumberdaya Hutan dan Ekowisata Fakultas Kehutanan Institut Pertanian Bogor.

Harso, T.K. (2010). Green Architecture : Pengantar Pemahaman Arsitektur Hijau Di Indonesia. Raja Grafind Persada : Jakarta.

Harsono, T., \& Martina R. (1998). Terites Sebagai Makanan Budaya Suku Batak Karo Suatu Tinjauan Etnobotani. Prosiding Seminar Nasional Etnobotani III. LIPI : Bogor.

Kumar,V.S.,Rahul S.,Satish, Shankul K., Sumit G., \& Ashutosh M. (2010). Antibacterial Activity of Leaves of Bamboo. Int. JPBS. 2(3) : 77-83.

Meita, F.P. (2013). Etnobotani Kelapa (Cocos nucifera L.) di Wilayah Denpasar dan Badung. Jurnal Simbiosis I.1(2) : 102-111.

Munziri, R.L., \& Mukarlina. (2013). Studi Etnobotani Bambu Oleh Masyarakat Dayak Kanayatn di Desa Saham Kecamatan Sengah Temila Kabupaten Landak. Protobiont. 2 (3) :112-116.

Natalia, M.N. (2009). Deskripsi Budidaya dan Pemanfaatan Bambu di Kelurahan Balumbang Jaya (Kecamatan Bogor Barat) dan Desa Rumpin (Kecamatan Rumpin) Kabupaten Bogor Jawa Barat. [Skripsi] Departemen Silvikultur Fakultas Kehutanan Institut Pertanian Bogor.

Pande, D.P., Wayan W., \& Nyoman S.A. (2012). Praktik Budi Daya Bambu Rebung Tabah. Udayana Universitas Press. Bali

Primair, A.Y. (2012). Keanekaragaman dan Populasi Bambu di Desa Talang Pauh Bengkulu Tengah. Jurnal Exacta. X (1) : $61-70$.

Razvi S.,Nautiyal S., Bakshi M., Bhat I,A.,Pala N.A. (2011). Influence of Season and Phytohormones on Rooting Behaviour of Green Bamboo by Cuttings. Int. JSC. 3(2) : 199-206.

Rifai, M.A. (1998). Pemasakinian Etnobotani Indonesia : Suatu Keharusan Demi Peningkatan Upaya Pemanfaatan, Pengembangan dan Penguasaannya. Prosiding Seminar Nasional Etnobotani III. LIPI. Bogor.

Sakaray,H,Vamsi N.V.K.T.. \& Ramana I.V.R. (2012). Investigation on Properties of Bamboo as Reinforcing Material in Concrete. Int. JERA. 2(1) : 77-83.

Sevalia,J.K.,Siddhpura N.B., Agrawal C.S., Shah D.B., \& Kapadia J.V. (2013). Study on Bamboo as Reinforcement in Cement Concrete. Int. JERA. 3(2) : 1181-1190.

Singh,K, Indra G., Sangeeta G. (2013). Classification of Bamboo Species by Fourier and Legendre Moment. Int. JAST. 50(1) : 61-70.

Soekarman., \& Sudarsono R. (1992). Status Pengetahuan Etnobotani di Indonesia. Didalam: Seminar dan Lokakarya Nasional Etnobotani; Cisarua-Bogor, 19-20 Februari 1992. Bogor: Departemen Pendidikan dan Kebudayaan RI,Departemen Pertanian RI, LIPI, Perpustakaan Nasional RI.Hal: 1-7.

Soetarno, H., Sri S.H., \& Sutiyono. (1996). Paket Modul Partisipatif : Budidaya Bambu Guna Meningkatkan Produktivitas Lahan. Prosea Indonesia : Bogor.

Soetjipto, B., \& Soenarto. (1990). Peralatan Produksi Tradisional dan Perkembangannya Di Daerah Jawa Timur. Departemen Pendidikan dan Kebudayaan : Jakarta.

Sudana, D., Dede K., Mahmud F., R. Dian D. Muniroh, Novi P., \& Nurshopia A. (2012). Eksplorasi Nilai Pendidikan Lingkungan Hidup Dalam Leksikon Etnobotani: Kajian Etnopedagogi di Kampung Naga, Kabupaten Tasikmalaya. Proposal Penelitian Hibah Penelitian Etnopedagogi. Jurusan Pendidikan Bahasa Inggris Fakultas Pendidikan Bahasa dan Seni Universitas Pendidikan Indonesia. Bandung

Supriati, R., Timi J., \& R.R. Sri A. (2013). Tumbuhan Obat yang dimanfaatkan oleh Masyarakat Desa Suka Rami Kecamatan air Nipis Kabupaten Bengkulu Selatan. Konservasi Hayati. 09 (02) : 33-43.

Syeda,A., \& Shrujal B.J.K (2014). A Case Study on Bamboo as Green Building Material. Int. JEAT. 4(2) :78-82.

Walujo, E.B. (1998). Etnobotani, Metode Penelitian Baru Penggabungan antara Konsep Ilmu -ilmu Sosial dan Ilmu Biologi. Prosiding Seminar Nasional Etnobotani III. LIPI. Bogor 
Walujo, E.B. (2009). Etnobotani : Memfasilitasi penghayatan, pemutakhiran pengetahuan dan kearifan lokal dengan menggunakan prinsipprinsip dasar ilmu. LIPI : Bogor.

Widjaja, E.A. (2001). Identikit Jenis-jenis Bambu di Jawa. Puslitbang Biologi LIPI : Bogor. 